\title{
Use of Misoprostol in the Management of Early Pregnancy LOSS
}

\author{
Gurung G, Rana A, Baral J \\ Department of Obstetrics and Gynecology, T.U. Teaching Hospital, Kathmandu, Nepal
}

Aims: To evaluate the effectiveness of Misoprostol administered vaginally to assist complete evacuation in early pregnancy losses (incomplete abortion, missed abortion and blighted ovum).

Methods: It is a descriptive study conducted in the Department of Ob/Gyn and Emergency Department Tribhuvan University Teaching hospital. All women with clinical/USG diagnosis of incomplete abortion, missed abortion and blighted ovum $\leq 12$ weeks POG either from last menstrual period (LMP) or USG were inserted tab. misoprostol $800 \mathrm{mcg}$ in the posterior fornix. Same dose was repeated when the evacuation was incomplete on day 3 of follow-up. Manual vacuum aspiration (MVA) was offered on day 14 if evacuation was incomplete or any complications like excessive bleeding/severe pain occurred during this period.

Results: A hundred and thirty three women with incomplete/missed/blighted ovum were reported, of which $112(84.3 \%)$ were analyzed as $21(15.7 \%)$ lost to follow up. Among the 112, 51 (45.5\%) were incomplete abortion, 34(30.3\%) blighted and $27(24.1 \%)$ missed abortion. Complete evacuation was achieved in 98/112 (87.5\%) cases [73 (65\%) cases with single dose \& 25(22.3\%) with double doses]. Evacuation was failed in $14(12.5 \%)$ cases [incomplete abortion $6(42 \%)$, blighted $7(50 \%) \&$ missed abortion $1(7.1 \%)$ ]. Failure for complete evacuation $(\mathrm{n}=14)$ related to gestational age: $10-12$ weeks $9 / 14(64 \%), 7-9$ weeks $5(35 \%)$ and none in the $\leq 6$ weeks. Although the plan was to evacuate on day 14 of follow-up for incomplete evacuation which was applicable only in 11(78.5\%) cases, 3(21.5\%) cases were surgically (MVA) treated beforehand ( 2 for excessive bleeding, 1 for severe pain). No severe complications and side effects requiring treatment were observed.

Conclusions: Vaginal Misoprostol is proved to be effective and safe in cases of incomplete abortion, missed abortion and blighted ovum. In the cases that failed to achieve complete evacuation by medical means using misoprostol were subjected to surgical manual vacuum aspiration (MVA) on day 14 of follow-up.

Keywords: Early pregnancy losses, misoprostol, manual vacuum aspiration.

\section{INTRODUCTION}

Early pregnancy losses continue to contribute high maternal mortality and morbidity especially in developing countries. Complications related to abortion are the third most common cause of maternal deaths in Nepal. ${ }^{1}$ About $10-20 \%$ of all clinically diagnosed pregnancy ends spontaneously. ${ }^{2}$ Among these spontaneous pregnancy losses eighty percent occurs within 12 weeks and the rate decreases thereafter. Chromosomal abnormalities are responsible for $50 \%$ of these losses.

By early pregnancy losses, we understand a range of conditions in which implanted fertilized ovum ceases to develop to the point of viability. These cases include spontaneous abortion like complete abortion in which cases all the product of conception has been expelled

\section{CORRESPONDENCE}

Prof. Geeta Gurung

Dept.of Obstetrics and Gynecology, T.U. Teaching Hospital

Kathmandu, Nepal

Phone: 9851046818

Email: gurunggeeta@hotmail.com and no intervention is needed; incomplete abortion in which some of the product of conception is retained; missed abortion where pregnancy has ended but no clear symptom of abortion is seen or there is spotting only and anembryonic or blighted ovum in which embryo has not developed within 12 weeks of pregnancy. ${ }^{3}$

Surgical management (dilatation and evacuation / manual vacuum aspiration) of these conditions has been the standard care worldwide for many years in the past. With the availability of the medical management options women are more interested to opt for this procedure which seems to be more natural than the surgical treatment and on top of that it is more convenient where surgical management is not available. Hence medical management is gaining attention as an effective, easy to use and low cost means of uterine evacuation. 
Misoprostol is one of the most commonly used such agents. Its effectiveness and safety have been established by multiple randomized and controlled trials. ${ }^{4,5}$ It is methyl ester of prostaglandin E1 which has a strong oxytocic effect and was originally used as a treatment of peptic ulcer disease induced by NSAIDs in 1980s. It is heat stable, doesn't need skilled manpower to use and reduces the use of surgical equipments, sterilization and so less invasive than the standard surgical treatment. It is presumed to be effective in the management of early pregnancy losses and surgery including its complications are believed to be avoided by $20 \%$ cases. $^{2}$ Misoprostol can be used by different routes like oral, sublingual, buccal, vaginal, and rectal. Different regimens and doses have been tried in different studies. ${ }^{6}$ The exact effective dose and route has yet to be find out.

The use of vaginal misoprostol is one of the medical management options of early pregnancy failure. Misoprostol is a stable drug which can be stored safely in room temperature. It is a non invasive procedure for which trained personnel is not needed and the patient doesn't need to be admitted in the hospital. Hence the aim of the study was to evaluate the effectiveness of vaginal Misoprostol in patients with early pregnancy failure.

If the study proves that misoprostol is effective with less side effects and complications it can be used as a routine management option for early pregnancy failure in low resource settings where trained manpower and cold chain is not available.

\section{METHODS}

A prospective study was conducted from Jesth 2066 to Asar 2067(May 2009-June 2010) in the OPD and Indoor of Department of Ob/Gyn, Emergency department of TU Teaching hospital, Kathmandu, Nepal.

Inclusion criteria being all women with clinical and USG findings of incomplete abortion/missed abortion/blighted ovum $\leq 12$ weeks according to last menstrual period (LMP). Exclusion criteria were spontaneous abortion with uterine scar e.g. Previous LSCS, classical CS scar, myomectomy scar, septic Induced abortion, Excessive bleeding with shock due to abortion, acute pelvic inflammatory disease,active liver, Renal, lung and heart disease and patients with known hypersensitive to E1 prostaglandin.

All patients fulfilling inclusion criteria were explained about the study thereafter included in the study after a written consent was obtained. Pretreatment detail history, general physical and pelvic examination was done and recorded. Pretreatment USG/TVS is done and the findings recorded. Patient was kept in dorsal position. Tab. misoprostol $800 \mathrm{mcg}$ (Cipla)was inserted in the posterior fornix. Patient remained lying in the same place for half an hour. All the danger signs were explained to the patient and were advised to attend emergency department in case of heavy bleeding, severe pain abdomen and fever. Patients were called on day 3 of the treatment for follow up. If the patient gave history of expulsion of product of conception transvaginal sonography (TVS) was done to confirm complete expulsion. If endometrial thickness was less than $1 \mathrm{~cm}$ complete evacuation was reported and patient was sent home suggesting to revisit in any case of complications. If no expulsion was noted by the patient or TVS showed incomplete evacuation $(\geq 1 \mathrm{~cm})$ a second dose of misoprostol $800 \mathrm{mcg}$ reinserted vaginally and the patient was sent home and advised to revisit on day 14 . On day 14 TVS is performed and if the uterine cavity was empty then the woman was released from the study. If the expulsion was not complete and the endometrial thickness was more than $1 \mathrm{~cm}$ manual vacuum aspiration (MVA) was offered and performed. All the patients were given prophylactic antibiotics of Doxycyclin $100 \mathrm{mg}$ BD for 5 days and Tinidazole $2 \mathrm{gm}$ stat per oral before the procedure. Tablet Meftal (Mefenamic acid) 500mg was offered for pain relief if needed.

\section{RESULTS}

Total of 133 women with incomplete/missed abortion/ blighted ovum were studied. Twenty one (15.7\%) lost to follow up, hence $112(84.3 \%)$ women were analyzed. Majority of the women were primigravida 61 (54.4\%), and $51(45.6 \%)$ were multigravida. Period of gestation when the women had abortion was $\leq 6$ weeks $6(5.3 \%)$, 7-9 weeks $48(48.8 \%)$ and $10-12$ weeks 58 (51.7\%). Fifty one (45.5\%) were incomplete abortion, 34(30.3\%) blighted and 27 (24.1\%) missed abortion.

\section{Table 1. POG and success rate}

\begin{tabular}{lllll}
\hline POG & success & failure & total & P value \\
\hline$\leq 6$ weeks & $6(100 \%)$ & $0(0 \%)$ & 6 & \\
$7-9$ weeks & $42(87.5 \%)$ & $6(12.5 \%)$ & 48 & 0.8448 \\
$10-12$ weeks & $50(86.3 \%)$ & $8(13.7 \%)$ & 58 & \\
\hline
\end{tabular}

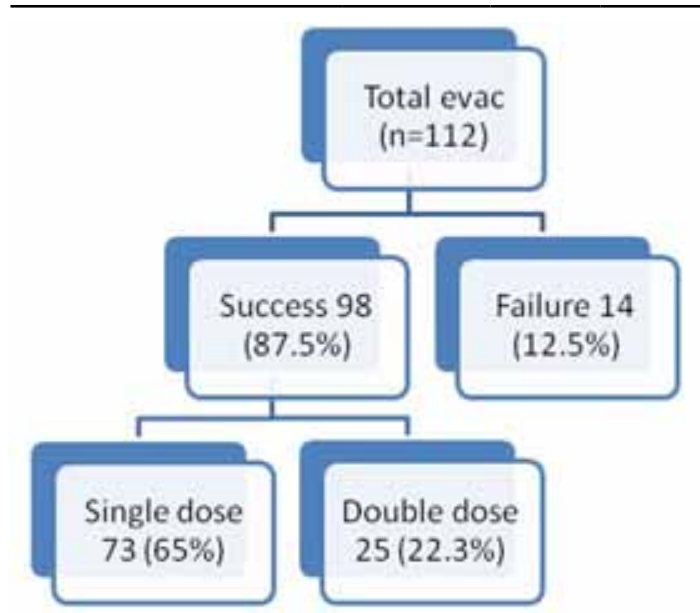

Figure 1. Success/failure rate 
Complete evacuation was achieved in 98 (87.5\%) cases [73(65\%) cases with single dose \& 25(22.3\%) with double doses] (fig.1). Among the successful cases ( $n=98)$, success was achieved $100 \%$ in the gestational age of $\leq 6$ weeks followed by $7-9$ weeks $87.5 \%(42), 86.3 \%$ (50 cases) in 10 12 weeks cases (table 1). Regarding the type of abortion $88.3 \%$ (45cases) was successful in incomplete group, $79.5 \%$ (27 cases) in blighted ovum group and $96 \%$ ( 26 cases) in missed abortion group (Table 2 ).

Table 2. Type of abortion and success rate

\begin{tabular}{llll}
\hline Type of abortion & Success & Failure & P value \\
\hline I n c o m p I e t e & $45(88.3 \%)$ & $6(11.7 \%)$ & \\
(n=51) & & & \\
Blighted ( $=34)$ & $27(79.5 \%)$ & $7(20.5 \%)$ & 0.1374 \\
Missed $(n=27)$ & $26(96.3 \%)$ & $1(3.7 \%)$ & \\
\hline
\end{tabular}

Evacuation was failed in $14(12.5 \%)$ cases of which incomplete abortion were 6(42\%), blighted $7(50 \%)$ \& missed abortion $1(7.1 \%)$. Among the failed group $(n=14)$, majority $8(57.1 \%)$ were in the gestational age of $10-12$ weeks, 6 (42.9\%) were 7-9 weeks, none in the $\leq 6$ weeks (table 4). All the failed groups $(n=14)$ were treated with MVA [11(78.5\%) for incomplete evacuation found on day 14 of follow-up, 2(14\%) for excessive bleeding and $1(7.1 \%)$ for severe pain on day1) ] (table 4).

Table 3. Analysis of failed group $(n=14)$

\begin{tabular}{lllll}
\hline Type \Wks & $\leq 6$ wks & $7-9$ wks & $10-12$ wks & total \\
\hline Incomplete & 0 & 2 & 4 & 6 \\
Blighted & 0 & 4 & 3 & 7 \\
Missed & 0 & 0 & 1 & 1 \\
Total & 0 & 6 & 8 & 14 \\
\hline
\end{tabular}

Table 4. Complications

\begin{tabular}{lll}
\hline & no & weeks \\
\hline Severe pain requiring MVA & $1(0.89 \%)$ & $10-12$ wks \\
Severe bleeding requiring MVA & $2(1.78 \%)$ & $10-12$ wks \\
Blood transfusion & 0 & \\
Infection & 0 & \\
\hline
\end{tabular}

Most common side effect observed was nausea 15(13.3\%) followed by diarrhea 11 (9.8\%), vomiting 7(6.25\%) and shivering $5(4.46 \%)$ each (table 5$)$. However all the side effects were mild and self limiting, not requiring any medication. Pain killer was needed for $64(73.57 \%)$ patients. The satisfaction of the women was enquired as like $72(64.2 \%)$, dislike $20(17.8 \%)$ and don't know $20(17.8 \%)$. Next time if such mishap occurs $14(12.35 \%)$ of them couldn't decide which method to use for evacuation, $12(10.7 \%)$ of them would leave the decision on the care provider, 21 (18.7\%) would opt for surgical evacuation and rest $65(58 \%)$ would go for medical abortion.
Table 5. Side effects observed

\begin{tabular}{ll}
\hline Side effects & No (\%) \\
\hline Nausea & $15(13.3 \%)$ \\
Diarrhea & $11(9.8 \%)$ \\
Vomiting & $7(6.25 \%)$ \\
Shivering & $5(4.46 \%)$ \\
\hline
\end{tabular}

\section{DISCUSSION}

Misoprostol is common oxytocic agent used to evacuate the uterus in cases of early pregnancy losses (incomplete, missed and blighted ovum). The present study shows the overall success rate of $800 \mathrm{mcg}$ of vaginally used misoprostol is $87.5 \%$ ( $65.2 \%$ with single dose and $22.3 \%$ with double dose).A similar study done by Zhang J et al ${ }^{7}$ showed $71 \%$ success rate with single and $84 \%$ with double dose of misoprostol. The slightly higher rate of success rate in the present study could be due to the longer follow up period (14 vs. 8 days.) Similar results (84-90\%) have been reported by different studies done in different setups. ${ }^{8-11}$ The varied result from different studies could be the different doses of misoprostol used and variable follow up period. Expulsion rate was found higher (60-90\%) when misoprostol is given $600-800$ mcg vaginally. ${ }^{7,12-13}$ This may be due to local effect on uterus, cervix and high drug concentration in uterine tissue and increased bioavailability with vaginal use. ${ }^{14,15}$

Regarding the success rate and type of abortion maximum success was achieved in missed abortion (96.3\%) followed by incomplete abortion (88.3\%) and blighted ovum (79.5\%). This finding does not match with the other studies done by Luise $\mathrm{C}$ et al and Zhang $\mathrm{J}^{7}$ et al where success of medical abortion was higher for incomplete and lower for blighted ovum compared to missed abortion. Similarly Demetroulis C13 also found that missed abortion to be slightly less easily and less successfully resolved with the use of misoprostol than incomplete abortion. The higher success rate of missed abortion in the present study could be because of the less number of missed abortion cases in comparison to incomplete and blighted abortion.

The present study found that smaller the gestational age the higher success rate. The success rate was $100 \%$ in the gestational age of $\leq 6$ weeks which was followed by $87 \%$ in the gestational age of 7-9 weeks and $86.3 \%$ in $10-12$ weeks; however the difference was statistically not significant.

Pain and bleeding are inevitable in the process of expulsion. Pain started within the first few hours and may be stronger than the regular period. Among the study population $73.5 \%$ used pain killer for relieving pain. Eighty three percent required analgesics in a study done by Blohm et $\mathrm{al}^{16}$ Pain killer can be used for pain relief without affecting the success of the method. ${ }^{17}$ Similarly among the failure group, the complications (severe pain and excessive bleeding requiring emergency 
surgical intervention) observed was $2 \%$ and all were in the gestational age group of 10-12 weeks, however nobody required blood transfusion. Study done by Zhang et al ${ }^{7}$ found complication in $<1$ in 70 patients and one woman $(0.2 \%)$ required emergency vacuum aspiration within 24 hours. Since the complications, though low in number were found especially in higher gestational age group the emergency surgical evacuation for 24 hours should be accessible to all those who are treated medically.

Infection was not common after medical abortion. It was nil in the present study population. Similarly Shannon et $\mathrm{al}^{18}$ also found a low number of infection rate $(0.92 \%)$. A fatal case of Clostridium sordellii after using vaginal misoprostol had been reported however after extensive investigation there is still no consensus as to the mechanism of infection in these cases..$^{19}$ Low infection rate in the present study could be explained with the use of prophylactic antibiotic in every cases.

The commonest side effect observed was nausea (13.3\%) followed by diarrhea (9.8\%), vomiting $(6.25 \%)$ and shivering (4.46\%). The side effects such as nausea, vomiting, diarrhea and shivering following use of vaginal misoprostol are self limiting and didn't require any medications as shown by the present study. Study done by Tang OS17 showed the diarrhea being the commonest side effect. Majority of the studies shows similar side effects. Chills in $32-57 \%$ and hyperpyrexia ( $>400 \mathrm{c}$ ) have been reported when used in the prevention of the postpartum hemorrhage.

The satisfaction of the women was enquired as like 72(64.2\%), dislike 20(17.8\%) and don't know 20(17.8\%). Slightly higher rate of satisfaction ( $86.6 \%$ and $88 \%$ ) with the procedure was found by Niinimaki et al. ${ }^{20}$ and Saguna et al. ${ }^{21}$

Next time if such mishap occured 65(58\%) would go for medical abortion, $14(12.35 \%)$ of them couldn't decide which method to use for evacuation, $12(10.7 \%)$ of them would leave the decision on the care provider, 21 (18.7\%) would opt for surgical evacuation. According to study done by Niinimaki et al $2070 \%$ would choose the medical method in future. Similarly in different studies 7, 19, 21, 22, 23 $70-93 \%$ women want to choose same if required.

The uncertain response rate (don't know and decision for method of evacuation if needed in the future) could be the low education level and lack of decision making power of our female population.

\section{CONCLUSIONS}

Vaginal Misoprostol, as a medical management is proved to be effective and safe in cases of incomplete abortion, missed abortion and blighted ovum upto 12 weeks of pregnancy. In the cases that failed to achieve complete evacuation by medical means using Misoprostol were subjected to surgical manual vacuum aspiration (MVA) on day 14 of follow-up. However provision of twenty four hour surgical evacuation service should be available for those who require emergency treatment.

\section{ACKNOWLEDGEMENT}

We would like to thank the Research Department, Institute of Medicine, Dean's Office for supporting the study and all the residents of the Department Ob/Gyn for helping on collecting the data.

\section{REFERENCES}

1. Family Health Division, Department of Health services, Government of Nepal. Nepal maternal mortality and morbidity study. 2008/2009, summary of preliminary finding.

2. Tang OS, Ho PC. The use of misoprostol for early pregnancy failure. Curr Opin Obstet Gynecol. 2006;18(6):581-6.

3. Winikoff B. Pregnancy failure and misoprostol-time for a change. $\mathrm{N}$ Engl J Med. 2005;353(8):834-6.

4. Blum J, Winikoff B, Gemzell-Danielsson K, Ho PC, Schiavon R, Weeks A. Treatment of incomplete abortion and miscarriage with misoprostol. Int J Gynecol Obstet. 2007;99(Suppl 2):9186.

5. Graziosi GC, van der Steeg JW, Reuwer PH, Drogtrop AP, Bruinse $\mathrm{HW}, \mathrm{Mol} \mathrm{BW}$. Economic evaluation of misoprostol in treatment of early pregnancy failure compared to curettage after an expectant management. Hum Reprod. 2005;20(4):1076.

6. Creinin MD, Harwood B, Guido RS, Fox MC, Zhang J. Endometrial thickness after misoprostol use for early pregnancy failure. Int Gynecol Obstet. 2004;86(1):22-6.

7. Zhang J, Gilles JM, Barnhart K, Creinin MD, Westhoff C, Frederick $\mathrm{MM}$, et al. A comparison of medical management with misoprosto and surgical management for early pregnancy failure. N Engl J Med. 2005;353(8):761-9.

8. Crinin MD, Harwood B, Guido RS, Fox MC Zhang J. NICHD management of early pregnancy failure trial. Int J Gynecol Obstet. 2004;86:22-6.

9. Davis $\mathrm{AR}$, Robilotto $\mathrm{CM}$, Westhoff $\mathrm{CL}$, Forman $\mathrm{S}$, Zhang J. Bleeding patterns after vaginal misoprostol for treatment of early pregnancy failure. Hum Reprod. 2004;19(7):1655-8.

10. Murchison A, Duff P. Misoprostol for uterine evacuation in patients with early pregnancy failures. Am J Obstet Gynecol. 2004;190(5):1445-6

11. Dempsey A, Davis A. Medical management of early pregnancy failure: how to treat and what to expect. Semin Reprod Med. 2008:26(5):401-10.

12. Neilson JP, Hickey M, Vazguez J. Medical treatment for early fetal death (less than 24 weeks).Cochrane Database Syst Rev. 2006;3:CD002253.

13. Demetraolis C, Saridogan E, Kunde D, Naftalin AA. A prospective randomized controlled trial comparing medical and surgical treatment for early pregnancy failure. Hum Reprod. 2001;16(2):365-9.

14. Zieman N, Fong SK, Benowitz NL, Banskter D, Darney PD. Absorption kinetics of misoprostol with oral or vaginal administration. Obstet Gynecol.1997;90(1):88-92. 
15. Khan RU, El-Refaey H, Sharma S, Sooranna D, Stafford M. Oral, rectal and vaginal pharmacokinetics of misoprostol. Obstet Gynecol. 2004;103:866-70.

16. Blohm F, Friden BE, Milsom I, Platz-Christensen JJ, Nielsen S. A randomized double blind trial comparing misoprostol or placebo in the management of early miscarriage. BJOG. 2005;112(8):1090-5

17. Tang OS, Gemzell-Danielsson K, Ho PC. Misoprostol: pharmacokinetic profiles, effects on the uterus and side-effects. Int J Gynecol Obstet. 2007; 99(supp 2):S160-7.

18. Shannon C, Brothers LP, Philip NM, Winikoff B. Infection after medical abortion: a review of the literature. Contraception.2004;70(3):183-90.

19. Fischer M, Bhatnagar J, Guarner J, Reagan S, Hacker JK, Van Meter SH et al Fatal toxic shock syndrome associated with Closttridium sordellii after medical abortion. N Eng J Med. 2005;353(22):2352-60.
20. Niinimaki $M$, Jouppila $P$, Martikainen $H$, Talvensaari-Matilla A. A randomized study comparing efficacy and patient satisfaction in medical or surgical treatment of miscarriage. Fertil Steril. 2006;86(2):367-72.

21. Saguna RK, Vidya AT, Shafia S.Vaginal misoprostol in early pregnancy failure. Al Ameen J Med Sci. 2010;3(3):195-200.

22. Blanchord K,Taneepanichskul S, Kinwat O.Two regimens of misoprostol for treatment of incomplete abortion for medical management of incomplete abortion. Contraception. 2005;72:438-42.

23. Ngoc NT, Blum J, Westheimer E, Quann TT, Winikoff B. Medical treatment of missed abortion using misoprostol. Int J Gynecol Obstet. 2004;87(2):138-42. 